\title{
The HGR motif is the antiangiogenic determinant of vasoinhibin: implications for a therapeutic orally active oligopeptide
}

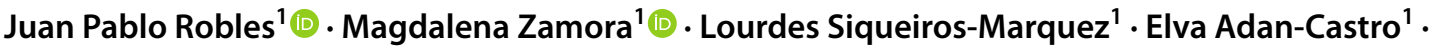 \\ Gabriela Ramirez-Hernandez ${ }^{1}$. Francisco Freinet Nuñez ${ }^{1}$. Fernando Lopez-Casillas ${ }^{2} \cdot$ Robert P. Millar $^{3,4}$. \\ Thomas Bertsch ${ }^{5}$. Gonzalo Martínez de la Escalera ${ }^{1}$ (i) - Jakob Triebel ${ }^{5}$ (i) Carmen Clapp $^{1}$ (i)
}

Received: 29 March 2021 / Accepted: 17 May 2021 / Published online: 7 June 2021

(c) The Author(s) 2021

\begin{abstract}
The hormone prolactin acquires antiangiogenic and antivasopermeability properties after undergoing proteolytic cleavage to vasoinhibin, an endogenous prolactin fragment of 123 or more amino acids that inhibits the action of multiple proangiogenic factors. Preclinical and clinical evidence supports the therapeutic potential of vasoinhibin against angiogenesis-related diseases including diabetic retinopathy, peripartum cardiomyopathy, rheumatoid arthritis, and cancer. However, the use of vasoinhibin in the clinic has been limited by difficulties in its production. Here, we removed this barrier to using vasoinhibin as a therapeutic agent by showing that a short linear motif of just three residues (His46-Gly47-Arg48) (HGR) is the functional determinant of vasoinhibin. The HGR motif is conserved throughout evolution, its mutation led to vasoinhibin loss of function, and oligopeptides containing this sequence inhibited angiogenesis and vasopermeability with the same potency as whole vasoinhibin. Furthermore, the oral administration of an optimized cyclic retro-inverse vasoinhibin heptapeptide containing HGR inhibited melanoma tumor growth and vascularization in mice and exhibited equal or higher antiangiogenic potency than other antiangiogenic molecules currently used as anti-cancer drugs in the clinic. Finally, by unveiling the mechanism that obscures the HGR motif in prolactin, we anticipate the development of vasoinhibin-specific antibodies to solve the on-going challenge of measuring endogenous vasoinhibin levels for diagnostic and interventional purposes, the design of vasoinhibin antagonists for managing insufficient angiogenesis, and the identification of putative therapeutic proteins containing HGR.
\end{abstract}

Keywords Vasoinhibin $\cdot 16 \mathrm{~K}$ prolactin $\cdot$ Angiogenesis $\cdot$ Vasopermeability $\cdot$ Oligopeptide $\cdot$ Retina $\cdot$ Melanoma

Juan Pablo Robles and Magdalena Zamora have contributed equally to this work.

Carmen Clapp

clapp@unam.mx

1 Instituto de Neurobiología, Universidad Nacional Autónoma de México (UNAM), Querétaro, México

2 Instituto de Fisiología Celular, Universidad Nacional Autónoma de México (UNAM), México City, México

3 Institute of Infectious Disease and Molecular Medicine, Department of Integrative Biomedical Sciences, Faculty of Health Sciences, University of Cape Town, Cape Town 7925, South Africa

4 Centre for Neuroendocrinology, Department of Immunology, Faculty of Health Sciences, University of Pretoria, Pretoria, South Africa

5 Institute for Clinical Chemistry, Laboratory Medicine and Transfusion Medicine, Nuremberg General Hospital \& Paracelsus Medical University, Nuremberg, Germany

\section{Introduction}

Abnormal angiogenesis underlies multiple diseases characterized by excessive or insufficient proliferation of blood vessels including cancer, vasoproliferative retinopathies, rheumatoid arthritis, diabetic ulcers, cardiovascular disease, and many others [1]. The concept of preventing disease progression by inhibiting angiogenesis has been extensively validated preclinically and clinically for the treatment of cancer and vasoproliferative retinopathies [2-4]. Inhibitors of tyrosine-kinase receptors [5] and monoclonal antibodies against VEGF [3] are the leading antiangiogenic compounds used clinically, albeit with drawbacks such as resistance, off-target effects, and toxicity [6, 7]. Also, several endogenous antiangiogenic proteins and protein fragments have been identified as potential therapeutic agents [8-10] with advantages of small size, lower immunogenicity, higher specificity, and lower risk of drug resistance [8, 11, 12]. 
However, some of these proteins are difficult to produce and have poor clinical performance [10,11].

Hormones regulate blood vessel growth and function [13]. They act directly on endothelial cells or indirectly, via the production of angiogenic and antiangiogenic mediators, and operate systemically to coordinate angiogenesis with other functions throughout the body [13]. Vasoinhibin is a proteolytically generated fragment of the hormone prolactin (PRL) that inhibits the proliferation, migration, survival, and permeability of endothelial cells [13, 14]. It binds to a multicomponent complex formed by plasminogen activator inhibitor-1, urokinase plasminogen activator, and the urokinase plasminogen activator receptor on endothelial cell membranes [15] to inhibit the signaling pathways (Ras-RafMAPK; Ras-Tiam1-Rac1-Pak1; PI3K-Akt; and PLCy-IP $3^{-}$ eNOS) activated by several proangiogenic and vasopermeability factors (VEGF, bFGF, IL-1 $\beta$, bradykinin) [13, 14]. Vasoinhibin is generated in the hypothalamus, the pituitary, and the target tissues defining the PRL/vasoinhibin axis [16]. Disruption of this axis can contribute to the progression of diabetic retinopathy $[17,18]$, retinopathy of prematurity [19], peripartum cardiomyopathy [20], pre-eclampsia [21], and rheumatoid arthritis [22]. However, translation of vasoinhibin into the clinic has been tempered by difficulties in its recombinant production [23]. We reasoned that the identification of the functional domain of vasoinhibin could lead to vasoinhibin-mimetics as alternative therapeutic molecules.

Vasoinhibin originates when the fourth a-helix (H4) of PRL is removed by specific proteolysis within loop 3 (L3) [13, 14, 24]. The structure of vasoinhibin is unknown, but molecular dynamic simulation showed that loss of $\mathrm{H} 4$ induces a new conformation in the first half of loop 1 (L1) that is absent in PRL and could expose the functional determinant of vasoinhibin (Fig. 1a) [25]. In agreement, a 79-residue protein comprising the $\mathrm{H} 1$ and $\mathrm{L} 1$ regions of human PRL [25] and a 14-residue oligopeptide corresponding to the L1 sequence of buffalo PRL [26] are antiangiogenic. Here, we have identified the functional determinant of vasoinhibin and translated it into easily produced soluble oligopeptides that inhibit angiogenesis and vasopermeability with the same potency as vasoinhibin.

\section{Materials and methods}

Materials and methods are detailed in the "Supplementary methods" section.

\section{Reagents}

Linear peptides ( $>95 \%$ pure) were commercially synthetized acetylated and amidated at the $\mathrm{N}$ - and C-termini, respectively
(Supplementary Table S2). The cyclic-retro-inverse-vasoinhibin-(45-51)-peptide (CRIVi45-51) (>98\% pure) was synthetized with the sequence ${ }_{\mathrm{D}} \mathrm{Ile}_{-}{ }_{\mathrm{D}} \mathrm{Phe}-\mathrm{Gly}{ }_{\mathrm{D}} \mathrm{Arg}-\mathrm{Gly}{ }_{\mathrm{D}} \mathrm{His}-$ ${ }_{\mathrm{D}} \mathrm{Thr}$ and head-to-tail cyclization (GenScript, Piscataway, $\mathrm{NJ})$. Recombinant vasoinhibin of 123 residues was produced as reported [27]. Recombinant human PRL was provided by Michael E. Hodsdon [28] (Yale University, New Haven, CT). Recombinant human vascular endothelial growth factor-165 (VEGF) was a gift from Genentech (South San Francisco, $\mathrm{CA}$ ) and basic fibroblast growth factor (bFGF) was donated by Scios, Inc. (Mountain View, CA). Bradykinin (BK) and interleukin-1 $\beta$ were purchased from Sigma-Aldrich (St. Louis, MO) and R\&D Systems (Minneapolis, MN), respectively. Anginex peptide was acquired from Phoenix Pharmaceuticals (Burlingame, CA), and cilengitide, human angiostatin K1-3, endostatin, pazopanib, sorafenib and sunitinib from Sigma-Aldrich (St. Louis, MO). Vasoinhibin and PRL cDNA were point-mutated by the two-step PCR technique, cloned in the pcDNA3 vector and produced by HEK293T/17 (ATCC, Manassas, VA) cells as reported [23].

\section{Molecular dynamic simulation}

Classical MD simulation was performed using GROMACS [29] using the coordinates of soluble human PRL (PDB: 1RW5) [30], as reported [25].

\section{Cell culture}

Human umbilical vein endothelial cells (HUVEC) were obtained [31] and cultured in F12K medium supplemented with $20 \%$ fetal bovine serum (FBS), $100 \mu \mathrm{g} \mathrm{mL}^{-1}$ heparin (Sigma-Aldrich), and $25 \mu \mathrm{g} \mathrm{mL}^{-1}$ ECGS (Corning, NY). The mouse melanoma B16-F10 cell line (CRL-6475, ATCC) was cultured in DMEM medium with 10\% FBS. All media contained $100 \mathrm{U} \mathrm{mL}^{-1}$ penicillin-streptomycin.

\section{Endothelial cell proliferation}

HUVEC were seeded at 14,000 cells $\mathrm{cm}^{-2}$ in a 96 -well plate and, after $24 \mathrm{~h}$, starved with $0.5 \%$ FBS for $12 \mathrm{~h}$. The medium was refreshed with 20\% FBS-F12K and incubated with $100 \mu \mathrm{g} \mathrm{mL}^{-1}$ heparin together with $25 \mathrm{ng} \mathrm{mL}^{-1}$ VEGF and $20 \mathrm{ng} \mathrm{mL}^{-1} \mathrm{bFGF}$ for $24 \mathrm{~h}$ in combination with a single dose $(100 \mathrm{nM})$ or different concentrations of PRL, vasoinhibin, or synthetic oligopeptides. DNA synthesis was quantified by the DNA incorporation of the thymidine analog 5-ethynyl-2'-deoxyuridine (EdU, Sigma) labeled by the click reaction with fluorescent Azide Fluor 545 (Sigma-Aldrich) as reported [25, 32]. 


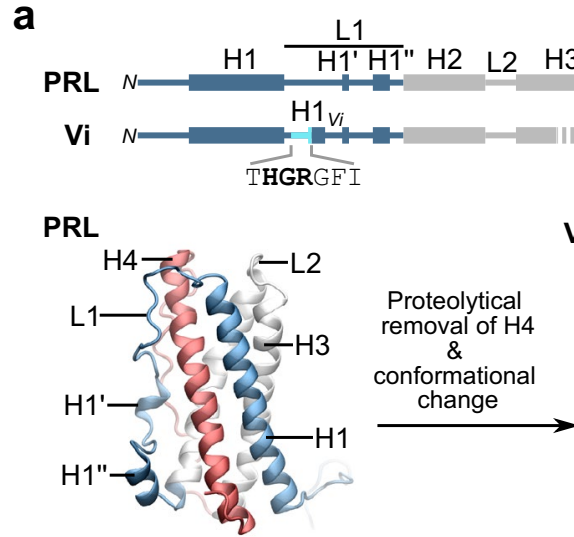

d

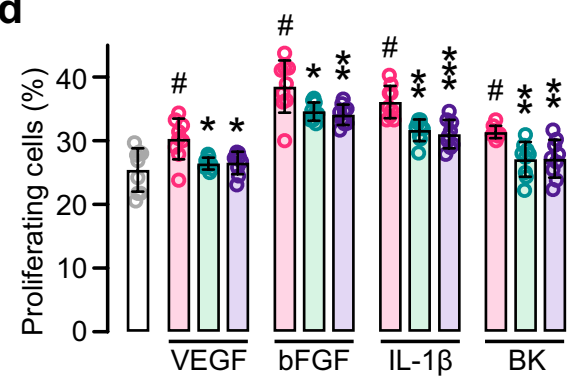

b
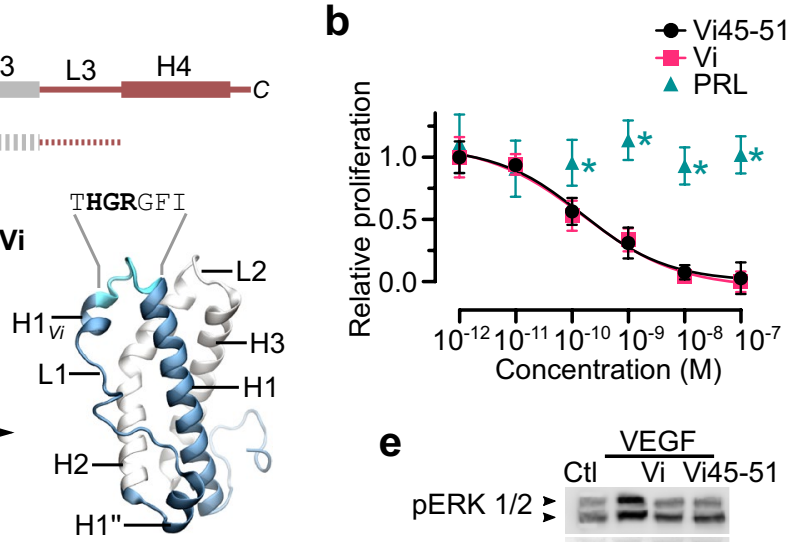

- Ctl

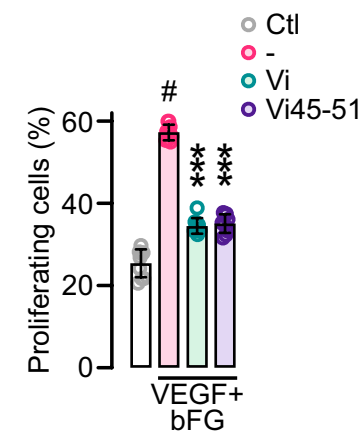

e
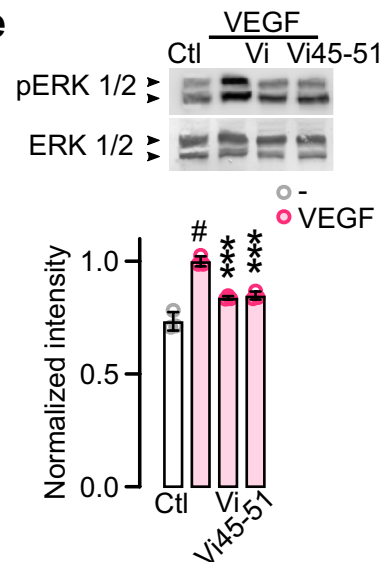

C

OVEGF

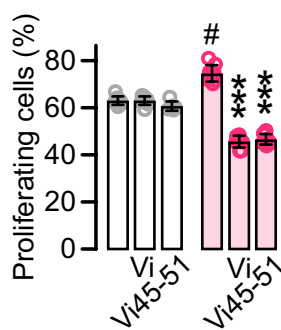

f

Sequence

Vi45-51 THGRGFI

Scramble $\mid \begin{array}{ll}1 & \text { GIGHFRT } \\ 2 & \text { THIRGGF } \\ 3 & \text { GTRIIHFG }\end{array}$

-VEGF+bFGF

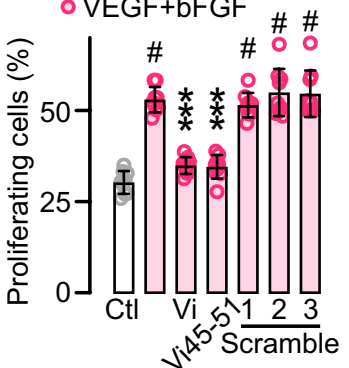

Fig. 1 THGRGFI heptapeptide mimics vasoinhibin. a Diagrams of secondary and tertiary structures of prolactin (PRL) and vasoinhibin (Vi) indicating $\alpha$-helixes (H1-4), loops (L1-3), and residues 45-51 corresponding to the THGRGFI. Vi originates when H4 is removed by specific proteolysis causing conformational changes in L1 including a new $\alpha$-helix $\left(H 1_{V i}\right)$. b Dose-response inhibition of HUVEC proliferation by the THGRGFI heptapeptide comprising residues 45-51 of Vi (Vi45-51), Vi of 123 residues (Vi), and PRL. Inhibition was against VEGF/bFGF-induced HUVEC proliferation. Proliferation relative to those of the lowest and highest dose of Vi positive control, $n=9, * P<0.001$ versus Vi (Two-way ANOVA, Dunnett). Doseresponse curves fitted by least square regression analysis $\left(r^{2}>0.9\right)$. Effect of $100 \mathrm{nM}$ Vi or Vi45-51 on BUVEC-E6E7 basal and VEGF-

\section{ERK1/2, Akt, and eNOS phosphorylation}

The protein of HUVEC cells treated or not with $100 \mathrm{nM}$ recombinant vasoinhibin or Vi45-51 followed by the addition or not of $100 \mathrm{ng} \mathrm{mL}^{-1}$ VEGF, was extracted in RIPA lysis buffer supplemented with 1:100 Halt Protease-Phosphatase Inhibitor cocktail and $5 \mathrm{mM}$ EDTA (both from Thermo Scientific). Proteins were resolved in SDS-PAGE followed by western blot as reported [25] with antibodies against phospho-ERK1/2 (9101, 1:500), phospho-Akt (9271, 1:500), or phospho-eNOS (9571, 1:250); and antibodies against total proteins ERK1/2 (9102, 1:500), Akt stimulated proliferation (c), or on human umbilical vein endothelial cell (HUVEC) proliferation stimulated by the proangiogenic factors VEGF, bFGF, IL-1 $\beta$, or bradykinin (BK), or the VEGF + bFGF combination (d). e Representative Western blot showing the effect of Vi or Vi45-51 on VEGF-induced phosphorylation (p) and total levels of ERK $1 / 2$ in HUVEC and the densitometric values of phosphorylated ERK $1 / 2$ after normalization for total ERK 1/2. f Effect of $100 \mathrm{nM}$ Vi, Vi45-51 and three different heptapeptides with Vi residues 45-51 in random order (scramble) on the VEGF+bFGF-induced proliferation of HUVEC. Proliferating cells are expressed relative to total cells. $* P<0.033, * * P<0.002, * * * P<0.001$ versus stimulated control; \# $P<0.001$ versus basal proliferation (Ctl) (Two-way ANOVA, Tukey). In all cases, values are means $\pm \mathrm{SD}, n=9$

(9272, 1:500), or eNOS (9572, 1:500), all from Cell Signaling (Danvers, MA).

\section{Endothelial cell motility assay}

The scratch wound healing assay evaluated cell motility [33]. HUVEC were grown to confluence on a 6-well plate and scratched using the edge of a cell scraper. The medium was replaced and IL-1 $\beta\left(10 \mathrm{ng} \mathrm{mL}^{-1}\right)$ was added to stimulate motility with or without $100 \mathrm{nM}$ of recombinant vasoinhibin or Vi45-51. After $16 \mathrm{~h}$, HUVEC migration was recorded with an inverted microscope and the 
area of wound sealing was calculated with the CellProfiler software [34]. The wound sealing area was expressed relative to the wound area and compared against cells treated with IL-1 $\beta$ alone.

\section{Endothelial cell invasion assays}

The transwell Matrigel barrier assay [35] evaluated cell invasion. HUVEC were seeded at 14,000 cells $\mathrm{cm}^{-2}$ on the upper (luminal) side of an 8 - $\mu \mathrm{m}$-pore insert coated with $0.38 \mathrm{mg} \mathrm{mL}^{-1}$ Matrigel (BD Biosciences, San Jose, $\mathrm{CA})$ in starvation medium (0.5\% FBS and no ECGS) with $100 \mathrm{nM}$ recombinant vasoinhibin or Vi45-51. Conditioned medium of 3T3-L1 cells containing 10\% FBS and VEGF (50 $\mathrm{ng} \mathrm{mL}^{-1}$ ) added to the lower (abluminal) chamber served as chemoattractant. After $16 \mathrm{~h}$, invading cells in the bottom side were fixed, permeabilized, stained and counted.

\section{Matrigel tube formation assay}

Formation of tubular endothelial cell networks was evaluated by the Matrigel tube formation assay as reported [36]. $\operatorname{HUVEC}\left(26,500\right.$ cells cm$\left.{ }^{-2}\right)$ were seeded onto a solid layer of Matrigel $\left(1.2 \mathrm{mg} \mathrm{cm}^{-2}\right)$ in a 24-well plate in the presence of $200 \mathrm{nM}$ recombinant vasoinhibin or Vi45-51 and incubated for $6 \mathrm{~h}$. Tube formation was quantified by Angiogenesis Analyzer for ImageJ software [37].

\section{Vasopermeability in vitro assays}

HUVEC monolayers were grown on $6.5 \mathrm{~mm}$ transwell with a $0.4 \mu \mathrm{m}$ pore. Trans-endothelial electrical resistance (TEER) was measured with the epithelial EVOM ${ }^{2}$ Volt/Ohm meter (World Precision Instruments, Sarasota, FL). Monolayers were treated with $100 \mathrm{nM}$ of recombinant vasoinhibin or Vi45-51 for $1 \mathrm{~h}$ before adding $50 \mathrm{ng} \mathrm{mL}^{-1}$ VEGF. TEER was measured over a 120 -min period. Albumin transit across HUVEC monolayers was evaluated 10 min after VEGF addition by adding Evans blue-linked albumin into the upper chamber and measuring its transit to the lower chamber.

\section{Actin distribution}

HUVEC cells seeded on Millicell EZ Slides (Millipore, Burlington, MA) were treated for $1 \mathrm{~h}$ with $100 \mathrm{nM}$ recombinant vasoinhibin or Vi45-51 followed by $200 \mathrm{ng} \mathrm{mL}^{-1}$ of VEGF for $1 \mathrm{~h}$. Cells were then fixed, permeabilized, and stained for actin with rhodamine phalloidin (Thermo Fisher Scientific).

\section{Heat and pepsin treatments}

Solutions $(2 \mu \mathrm{M})$ of recombinant vasoinhibin, Vi45-51, or CRIVI45-51 were heat-inactivated $\left(97^{\circ} \mathrm{C}, 15 \mathrm{~min}\right)$ or digested with pepsin (Sigma-Aldrich) by incubating $4 \mu \mathrm{M}$ of each vasoinhibin at a final 1:20 protease to substrate molar ratio in $40 \mathrm{mM} \mathrm{HCl}\left(37^{\circ} \mathrm{C}\right.$ for $\left.5 \mathrm{~h}\right)$.

\section{Animals}

Male Wistar rats, and male and female C57BL6 and CD1 mice were housed under standard laboratory conditions. All interventions were carried out under $2.5 \%$ isoflurane anesthesia (SomnoSuite system, Kent Scientific, Torrington, $\mathrm{CT}$ ). Experiments were approved by the Bioethics Committee of the Institute of Neurobiology of the National University of Mexico (UNAM) according to the US National Research Council's Guide for the Care and Use of Laboratory Animals (Eighth Edition, National Academy Press, Washington, D.C., USA).

\section{Matrigel plug angiogenesis assay}

The Matrigel plug assay was performed [38] and quantified [39] as reported. Matrigel plug (0.5 mL, BD Biosciences) was supplemented with $300 \mathrm{ng} \mathrm{mL}^{-1}$ bFGF and $1 \mu \mathrm{M}$ recombinant vasoinhibin or Vi45-51.

\section{Retinal angiogenesis assay}

Retinal angiogenesis was determined in CD1 neonate mice as reported [40]. Vi45-51 $\left(300 \mu \mathrm{g} \mathrm{kg}^{-1}\right)$ or vehicle were administered intraperitoneally every $12 \mathrm{~h}$ from postnatal day (P) 3 to 8. Pups were euthanized by carbon dioxide inhalation and decapitation at P8, and retinas flat-mounted or frozen to evaluate blood vessels by immunofluorescence or RT-qPCR, respectively.

\section{Retinal vasopermeability assay}

The retinal vasopermeability assay was carried out as previously described [41]. Male Wistar rats (300 g) anesthetized with $70 \%$ ketamine and $30 \%$ xylazine $\left(1 \mu \mathrm{L} \mathrm{g}^{-1}\right)$ were intravitreally injected with $3 \mu \mathrm{L}$ of vehicle (PBS) containing or not $200 \mathrm{ng}$ of VEGF with or without $20 \mu \mathrm{M}$ recombinant vasoinhibin or Vi45-51, and retinal vasopermeability was evaluated after $24 \mathrm{~h}$ by fluorescein angiography or the Evans blue method. 


\section{Tumor model}

The mouse model of primary tumor development based on the use of B16-F10 melanoma cells was used as previously reported [42]. Briefly, anesthetized female C57BL6 mice (8-12 weeks-old) were inoculated into their right flank with $10^{5}$ B16-F10 cells. Five days after tumor cell inoculation, mice were treated daily with vehicle (NS) or CRIVi45-51 injected into the lateral tail vein or via intragastric gavage for the $8 \mathrm{~d}$ following tumor cell injection. Animals were then euthanized by cervical dislocation and the tumors weighted and processed to evaluate blood vessels by immunofluorescence or RT-qPCR.

\section{Statistical analysis}

The dose-response curves were fitted by least square regression analysis with a variable slope model calculated with at least 54 points. The unpaired t-test was used when there were two independent groups. For more than two groups One-way or Two-way ANOVA followed by the Dunnett test (when compared to a control) or Bonferroni or Tukey test (when comparing to every other group) were performed in GraphPad Prism version 8.4.3 for MacOS, GraphPad Software, San Diego, California USA. The overall significance threshold was set at $P<0.05$.

\section{Results}

\section{The HGR motif is the antiangiogenic determinant of vasoinhibin}

To precisely locate the antiangiogenic determinant of vasoinhibin, we scanned synthetic oligopeptides along the 45-58 residue sequence of human PRL for their ability to inhibit endothelial cell (EC) proliferation (Supplementary Fig. 1). A heptapeptide corresponding to residues $45-51$ of vasoinhibin (Vi45-51) inhibited EC proliferation with a potency $\left(\mathrm{IC}_{50} \sim 150 \mathrm{pM}\right)$ and profile similar to a conventional vasoinhibin of 123 residues (Fig. 1b). Like vasoinhibin [13, 14], Vi45-51 did not affect basal EC proliferation (Fig. 1c), antagonized the EC proliferation induced by various proangiogenic factors (VEGF, bFGF, IL-1 $\beta$, and bradykinin) a

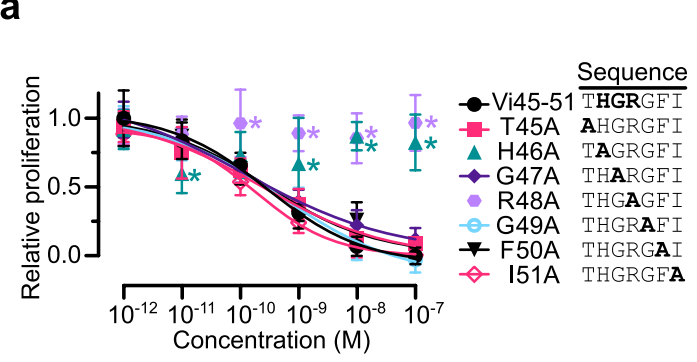

d

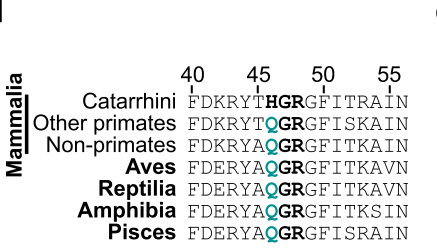

e

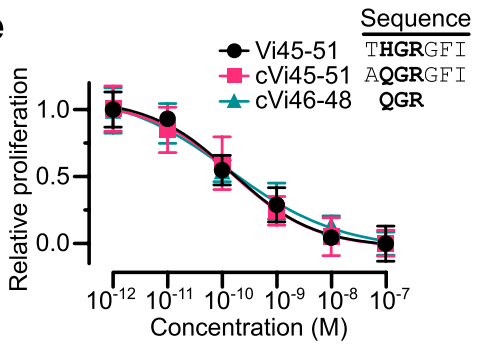

b

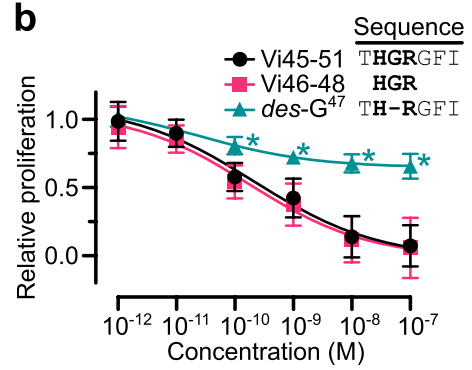

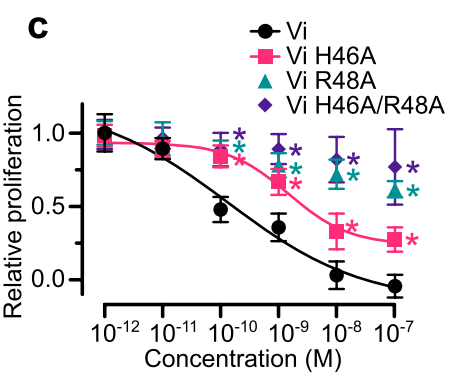

Concentration (M)

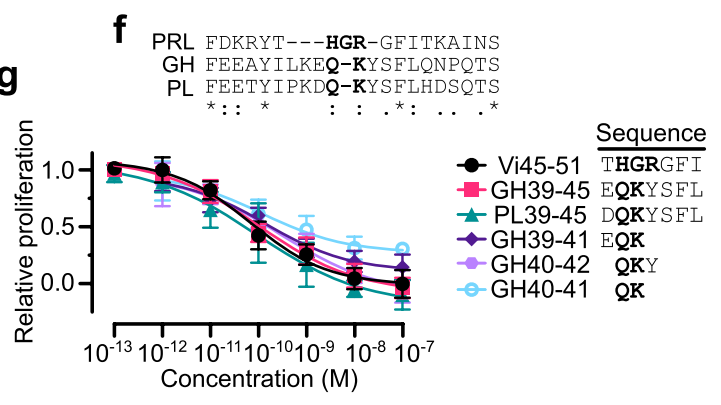

Fig. 2 HGR motif is the antiangiogenic determinant of vasoinhibin. Dose-response inhibition of VEGF+bFGF-induced HUVEC proliferation by: Vi45-51 subjected to alanine scanning mutagenesis (a); by Vi45-51, HGR tripeptide (Vi46-48), and Vi45-51 with G47 deleted $\left(\right.$ des $\left.-\mathrm{G}^{47}\right)(\mathbf{b})$; and by vasoinhibin of 123 amino acids (Vi) or Vi alanine mutants H46A, R48A, or H46A/R48A (c). d Alignment of vertebrate PRL sequences. Conserved HGR residues in bold and substitution of $\mathrm{H}$ by $\mathrm{Q}$ in green. e Dose-response inhibition of VEGF + bFGF-induced HUVEC proliferation by Vi45-51, its Q-substituted conserved version (cVi45-51), and the QGR tripeptide (cVi46-48). f Alignment of human PRL, GH, and PL sequences indicating same $\left(^{*}\right)$, similar (:), less similar (.), and dissimilar (blank) res- idues. The HGR motif (residues 46-48) in PRL and the putative Q-K motif in GH and PL (residues 40-41) are in bold. g Dose-response inhibition of HUVEC proliferation by Vi45-51, heptapeptides comprising residues 39-45 of GH (GH39-45) and PL (PL39-45), EQK and QKY tripeptides (GH39-41 and GH40-42, respectively) and the QK dipeptide (GH40-41). Inhibition was against VEGF/bFGFinduced HUVEC proliferation. Values are means \pm SD relative to those of the lowest and highest dose of $\mathrm{Vi}$ or Vi45-51 positive controls, $n=9, * P<0.001$ versus Vi45-51 or Vi (Two-way ANOVA, Dunnett). Dose-response curves fitted by least square regression analysis $\left(r^{2}>0.8\right)$ 
(Fig. 1d), and prevented the VEGF-induced activation of the MAPK pathway (Fig. 1e). Moreover, three different scrambled heptapeptides failed to inhibit EC proliferation indicating that the Vi45-51 sequence is required for activity (Fig. 1f).

The HGR motif is essential for vasoinhibin activity. Alanine-scanning revealed that $\mathrm{H} 46 \mathrm{~A}$ or $\mathrm{R} 48 \mathrm{~A}$ were the only mutations abolishing the activity of the heptapeptide (Fig. 2a), deletion of G47 (des $-\mathrm{G}^{47}$ ) resulted in loss of function, and the synthetic HGR tripeptide (Vi46-48) displayed full activity (Fig. 2b). Furthermore, R48A and H46A/R48A mutants of the 123-residue vasoinhibin showed no antiangiogenic activity, whereas the sole mutation of H46 to A46 resulted in a reduced effect (Fig. 2c). These findings identify HGR as the essential element responsible for the antiangiogenic activity of full-length vasoinhibin.

The essential role of HGR is further supported by its evolutionary conservation. It is conserved in the PRL of high order primates and in other vertebrates $\mathrm{H}$ is replaced by glutamine (Q), a conservative substitution (Fig. 2d). The conserved heptapeptide (cVi45-51) with H46Q and the QGR tripeptide (cVi46-48) displayed activity equal to Vi45-51 (Fig. 2e).

Because PRL is structurally and functionally related to growth hormone $(\mathrm{GH})$ and placental lactogen (PL), which are also cleaved to vasoinhibin [13, 43], we aligned their human sequences, synthetized two heptapeptides comprising residues 39-45 of GH and PL, and showed that both of them inhibited EC proliferation with the same potency as Vi45-51 (Fig. 2f, g). Thereby, the location of the antiangiogenic domain is similar among the three hormones and, although GH and PL lack the HGR sequence, they contain Q40-K41 as a putative HGR-like motif. Like Q and H, K is a conservative substitution for $\mathrm{R}$, and tripeptides EQK and QKY and dipeptide QK displayed similar activity than Vi45-51. a

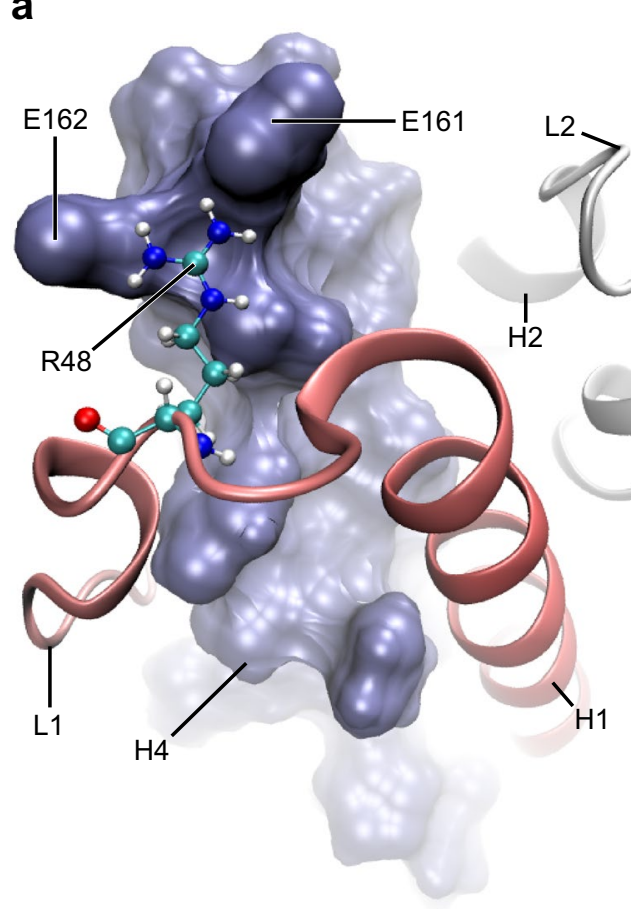

b

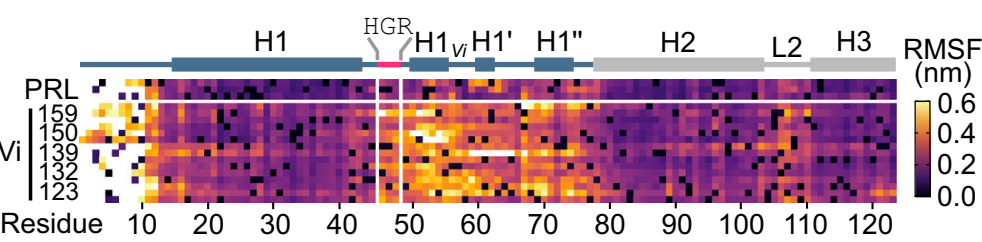
2 4

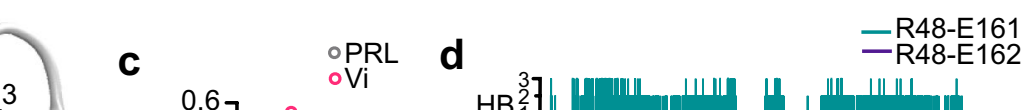<smiles>[AlH2]C1CCCC1</smiles>

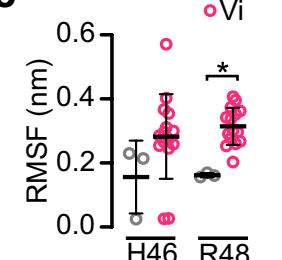

e $\rangle_{E 162}$

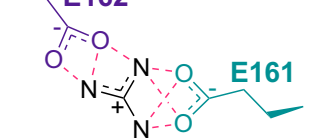

f
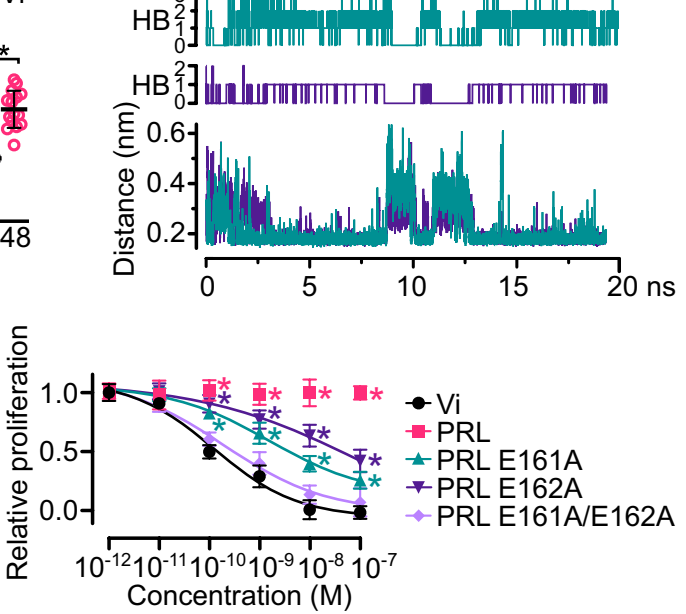

Fig. 3 E161 and E162 in PRL obscure the HGR motif by salt bridges restraining R48. a Detail of the interaction between R48 (balls and sticks) and E161 and E162 in the N-terminal region of $\alpha$-helix 4 (H4) (blue surface). R48 is located in loop 1 (L1) near $\alpha$-helix 1 (H1) (red ribbon). b Root mean square fluctuation (RMSF) of the first 123 residues of PRL and vasoinhibin (Vi) of different lengths (159, 150, 139, 132 , and 123 residues) over $20 \mathrm{~ns}$ molecular dynamic (MD) simulation. Location of HGR, $\alpha$-helixes (H1-3), and loops (L1-2) are indicated in the diagram above. c RMSF of H46 and R48 in PRL and $\mathrm{Vi}$ isoforms. Values are means $\pm \mathrm{SD}, n=3-9, * P=0.042$ (Two-way ANOVA, Bonferroni). d Formation of hydrogen bonds (HB) between
R48 and E161 and R48 and E162 in PRL and their correlation with the minimum distance between the residue pairs revealed by MD simulation. e Molecular scheme showing the three and four possible hydrogen bonds (red dashed lines) formed between the side chains of R48 and E162 and E161, respectively. e Dose-dependent inhibition by Vi of 123 residues (Vi), PRL, or PRL mutants where E161, E162, or E161 and E162 were replaced by alanine on VEGF + bFGFinduced proliferation of HUVEC. Values are means \pm SD relative to those of the lowest and highest dose of the Vi positive control, $n=9$, $* P<0.001$ versus Vi (Two-way ANOVA, Dunnett). Dose-response curves fitted by least square regression analysis $\left(r^{2}>0.9\right)$ 


\section{Molecular mechanism encrypting the HGR motif in PRL}

The fact that PRL is not antiangiogenic [13, 14] (Fig. 1b) implies that HGR is cryptic in PRL and only exposed after removal of H4. The analysis of the HGR region in the structure of human PRL $[28,30]$ revealed that R48 is in contact with glutamic acids 161 and 162 (E161 and E162) (EE) located in the amino terminal region of H4 (Fig. 3a; Supplementary Fig. 2a, b). Hence, we speculated that salt bridges involving the positive charge of R48 and the negative electrostatic potential of E161 and E162 restrict the mobility of HGR preventing its activity (Supplementary Fig. 2c).
Indeed, molecular dynamic simulation showed that the fluctuation of residues within L1, including $\mathrm{H} 46$ and $\mathrm{R} 48$, is higher in various vasoinhibin isoforms than in PRL (Fig. 3b, c) in which R48 forms up to 3 and 2 hydrogen bonds with E161 and E162 at minimum distance, respectively (Fig. 3d, e). Moreover, this EE motif is found in primates and rodents, and in all other vertebrates E162 is replaced by aspartic acid (D), a similar negatively charged residue (Supplementary Fig. 2d). The role of these residues in restraining antiangiogenic activity in full-length PRL is cogently supported by the demonstration that removal of these acidic side chains by alanine substitution confers antiangiogenic properties upon full-length PRL (Fig. 3f). We conclude that salt bridges

a
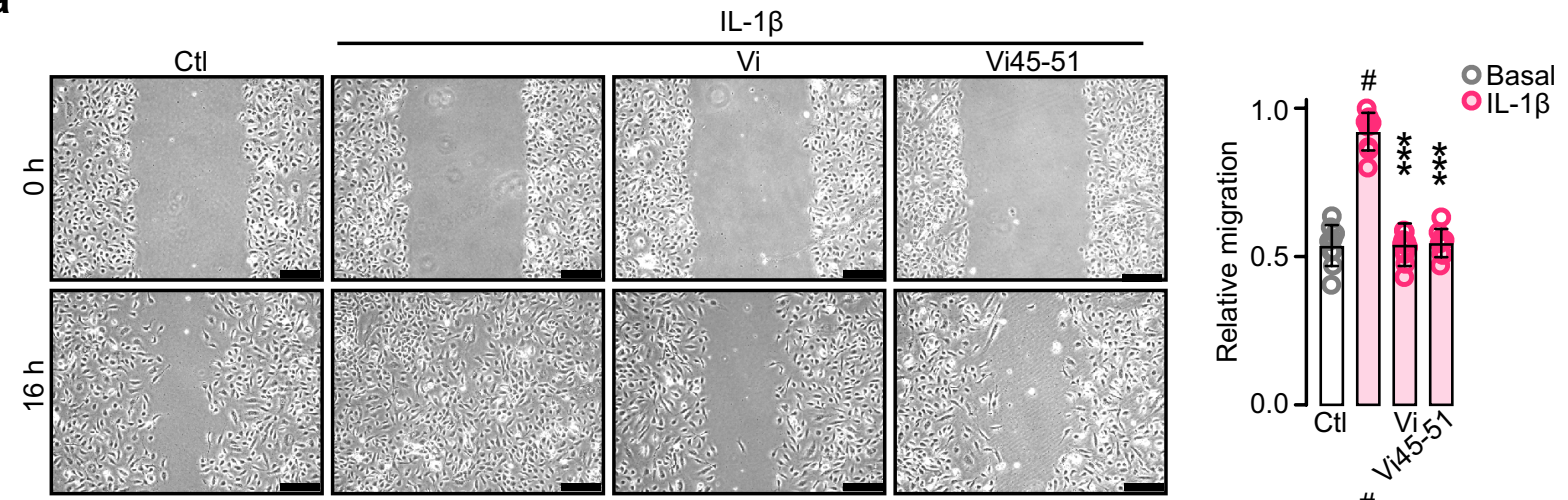

b
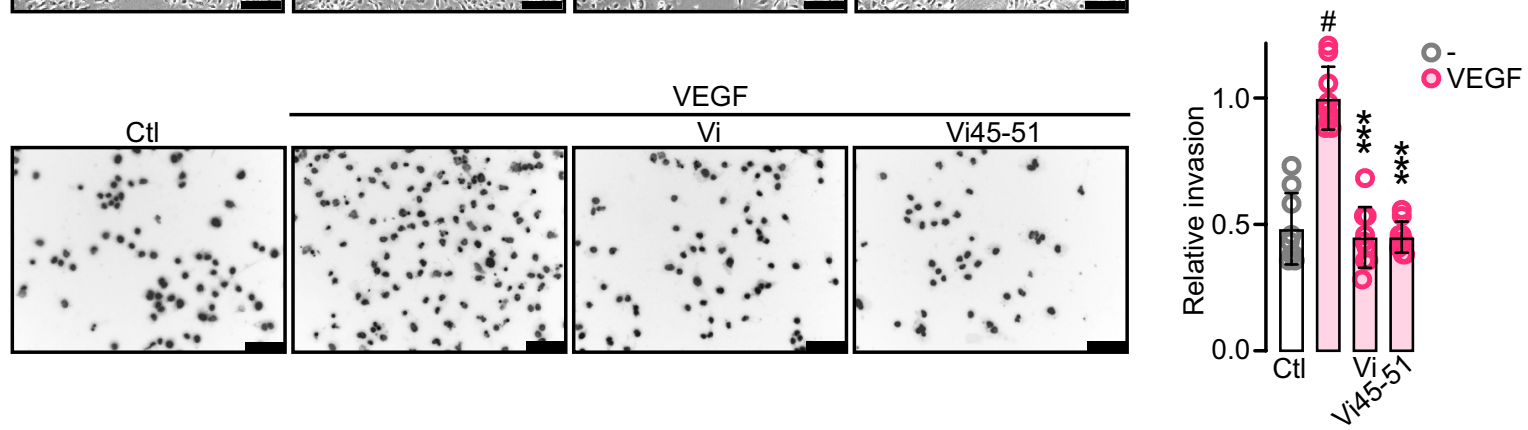

C
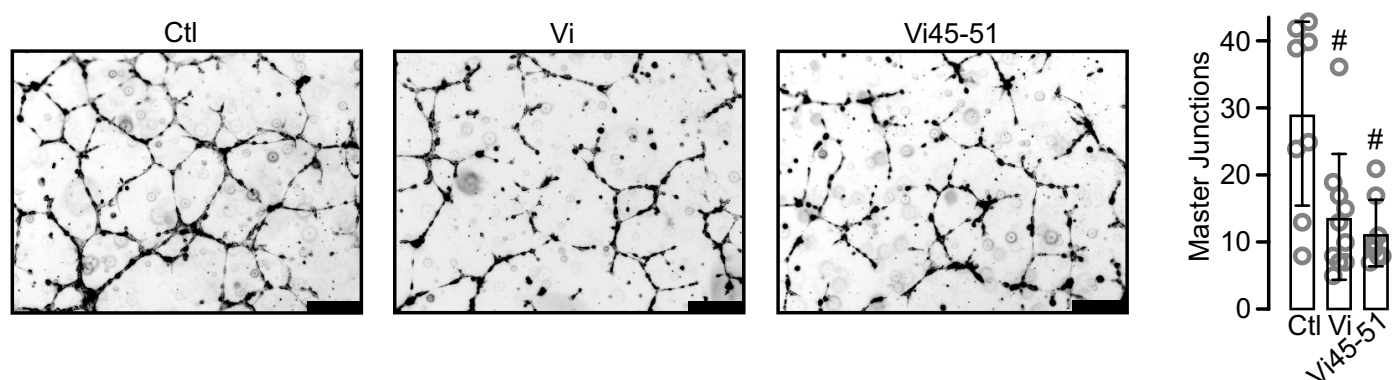

Fig. 4 Vasoinhibin heptapeptide (Vi45-51) containing the HGR motif inhibits angiogenesis in vitro. a HUVEC monolayers at 0 and $16 \mathrm{~h}$ after wound scratch incubated in the absence $(\mathrm{Ctl})$ or presence of IL-1 $\left(10 \mathrm{ng} \mathrm{mL}^{-1}\right)$ alone or together with $100 \mathrm{nM}$ vasoinhibin of 123 residues (Vi) or Vi45-51. Values represent the area occupied by migrating cells relative to the initial wound area. b Inhibition of HUVEC invasion across a Matrigel barrier by $100 \mathrm{nM} \mathrm{Vi}$ or
Vi45-51. VEGF (50 $\mathrm{ng} \mathrm{mL}^{-1}$ ) was used as chemoattractant. Values are number of invading cells relative to those with VEGF alone. c Inhibition of HUVEC tube-network formation by $200 \mathrm{nM} \mathrm{Vi}$ or Vi45-51 quantified by number of master junctions. $* * P<0.01$, $* * * P<0.001$ versus stimulated control, \# $P<0.01$ versus Ctl. Values are means $\pm \mathrm{SD}, n=9$, compared by Two-way ANOVA-Dunnett. Scale bar: $300 \mu \mathrm{m}$ 
a

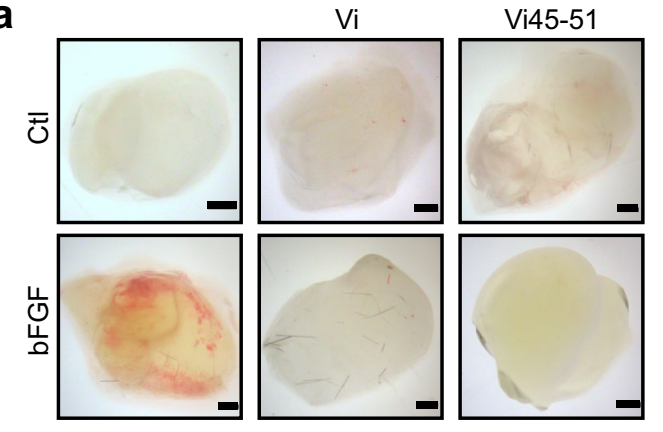

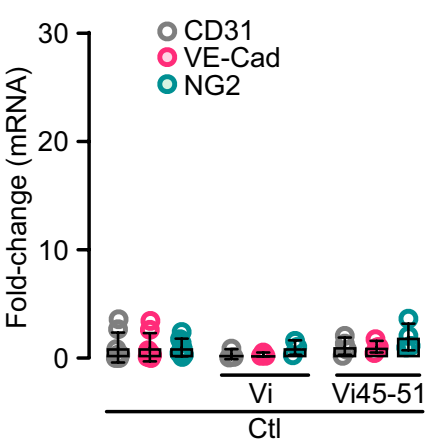

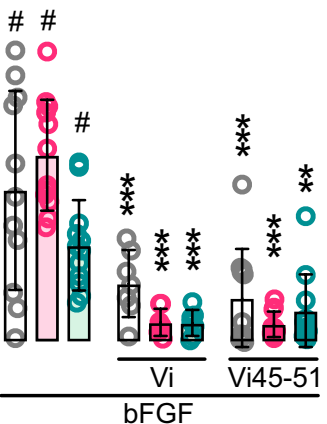

b
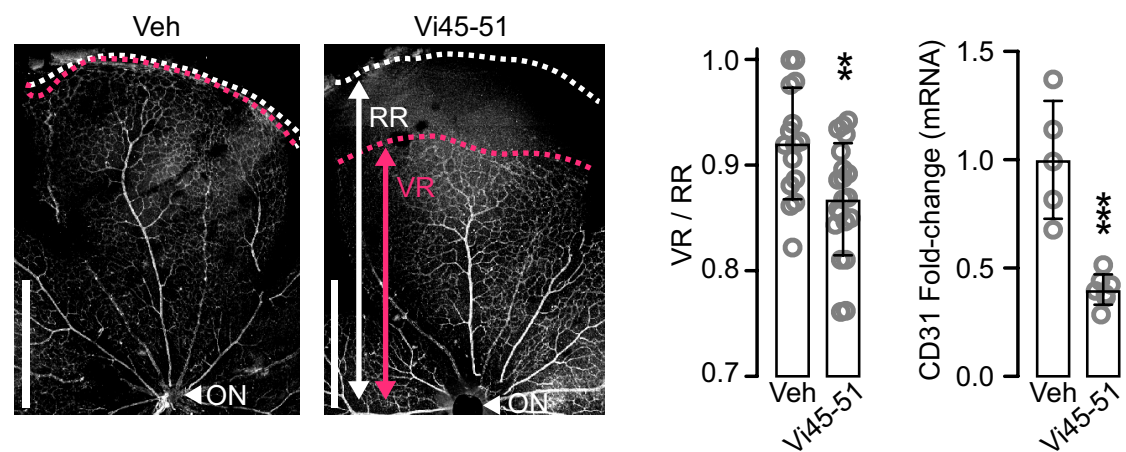

Fig. 5 Vasoinhibin heptapeptide (Vi45-51) containing the HGR motif inhibits angiogenesis in vivo. a Matrigel plugs $6 \mathrm{~d}$ after mice implants without $(\mathrm{Ctl})$ or with bFGF containing or not Vi or Vi4551. mRNA expression of endothelial cell (CD31 and VE-Cad) and pericyte (NG2) markers in plugs. $* * P<0.01$, $* * * P<0.001$ versus bFGF; \# $P<0.001$ versus Ctl. b CD31-immunostained flat-mounted

between R48 and E161 and E162 obscure the HGR sequence in PRL rendering it unable to inhibit angiogenesis.

\section{The vasoinhibin heptapeptide (Vi45-51) containing the HGR motif inhibits angiogenesis and vasopermeability}

Angiogenesis is a multistep process involving the proliferation, migration, and tube formation of EC, all of which are downregulated by vasoinhibin [13, 14, 24]. Consistent with HGR being the vasoinhibin antiangiogenic determinant, Vi45-51 inhibited IL-1 $\beta$-induced EC motility (Fig. 4a), VEGF-induced EC invasion (Fig. 4b), and EC tube formation (Fig. 4c). Furthermore, Vi45-51 inhibited the entire process of in vivo angiogenesis. Vi45-51 blocked the bFGF-induced invasion of blood vessels into subcutaneously implanted Matrigel plugs in mice (Fig. 5a) and reduced physiological angiogenesis in the new-born mouse retina. In rodents, the retinal vasculature sprouts and spreads radially after birth completing vascularization after the first postnatal week [44]. Daily intraperitoneal injections of Vi45-51 interfered with the retinas from postnatal d 8 neonate mice injected with vehicle (Veh) or Vi45-51. Radial vascular expansion from the optic nerve (ON) evaluated by the index between vascular (VR) and retinal (RR) ratios and by retinal CD31 mRNA levels. $* * P<0.01, * * * P<0.001$ versus Veh. (Unpaired $t$-test). Values are means $\pm \mathrm{SD}, n=9$. Scale: $1 \mathrm{~mm}(\mathbf{a})$, $500 \mu \mathrm{m}(\mathbf{b})$

completion of retinal vascularization, indicating impaired angiogenesis (Fig. 5b).

Vasoinhibin also inhibits the excessive vascular permeability present in diseases such as diabetic macular oedema, diabetic retinopathy $[41,45,46]$, and inflammatory arthritis [22]. Like vasoinhibin [45, 46], Vi45-51 blocked VEGFinduced hyperpermeability of EC monolayers as assessed by actin cytoskeleton distribution (Fig. 6a), transendothelialelectrical resistance (TEER) (Fig. 6b), and flux of Evans blue-linked albumin (Fig. 6c). Furthermore, Vi45-51 reduced the retinal extravasation of fluorescent dextran and Evans blue-linked albumin in response to the intravitreal injection of VEGF in rats (Fig. 6d, e). Vasoinhibin inhibits hyperpermeability by blocking eNOS activation and the production and effects of $\mathrm{NO}$ on adherent junctions [45, 46], and Vi45-51 also blocked the VEGF-induced phosphorylation/activation of AKT and eNOS (Fig. 6f). Taken together our findings indicate that HGR is the common structural element responsible for vasoinhibin vascular actions, and that oligopeptides containing HGR hold promise for the treatment of angiogenesis- and vascular permeability-dependent diseases. However, the comparison between in vitro-in vivo 
a

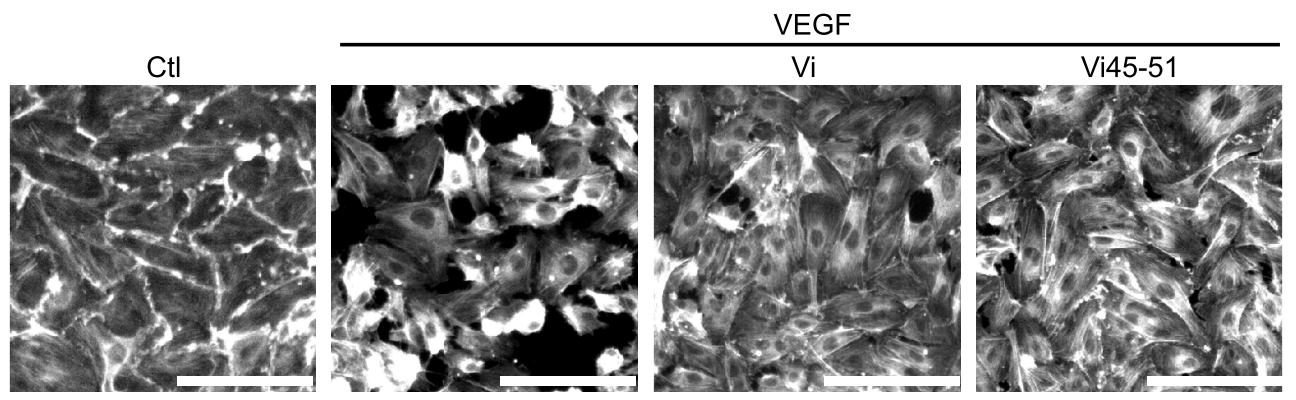

b
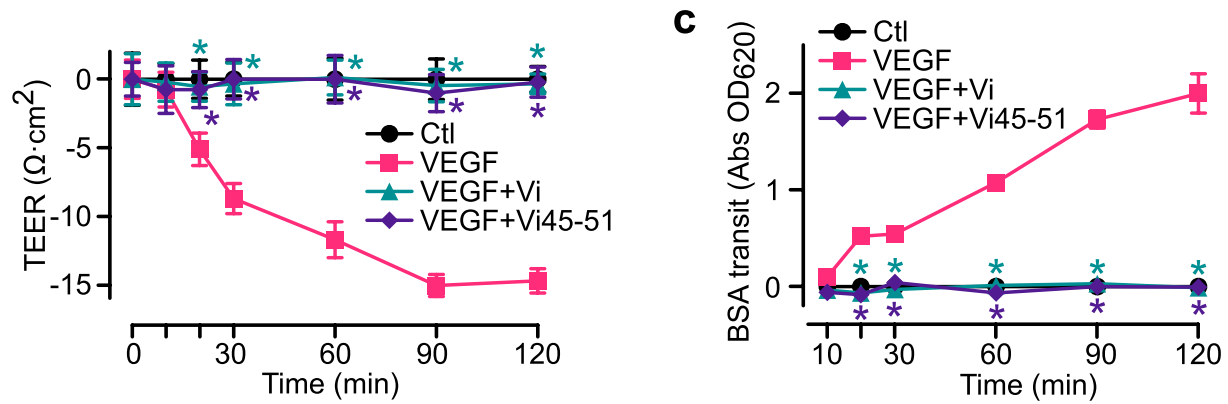

d
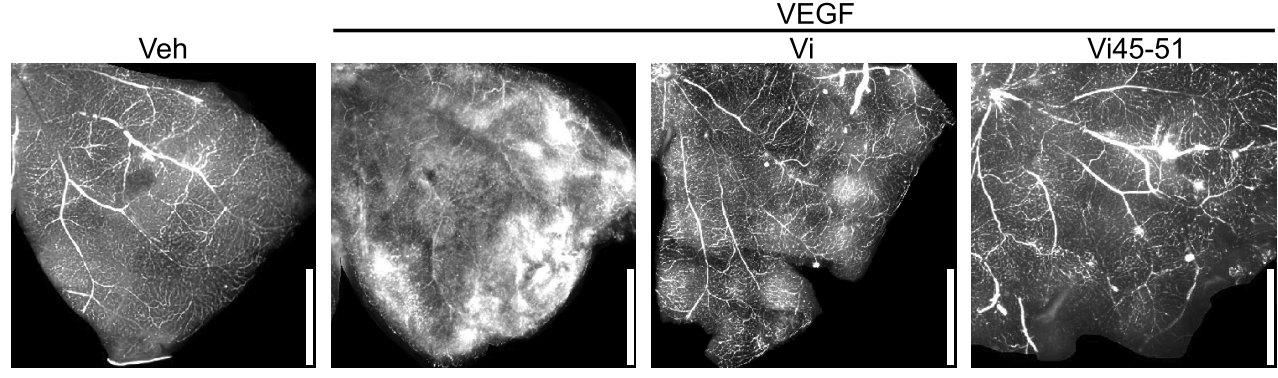

e
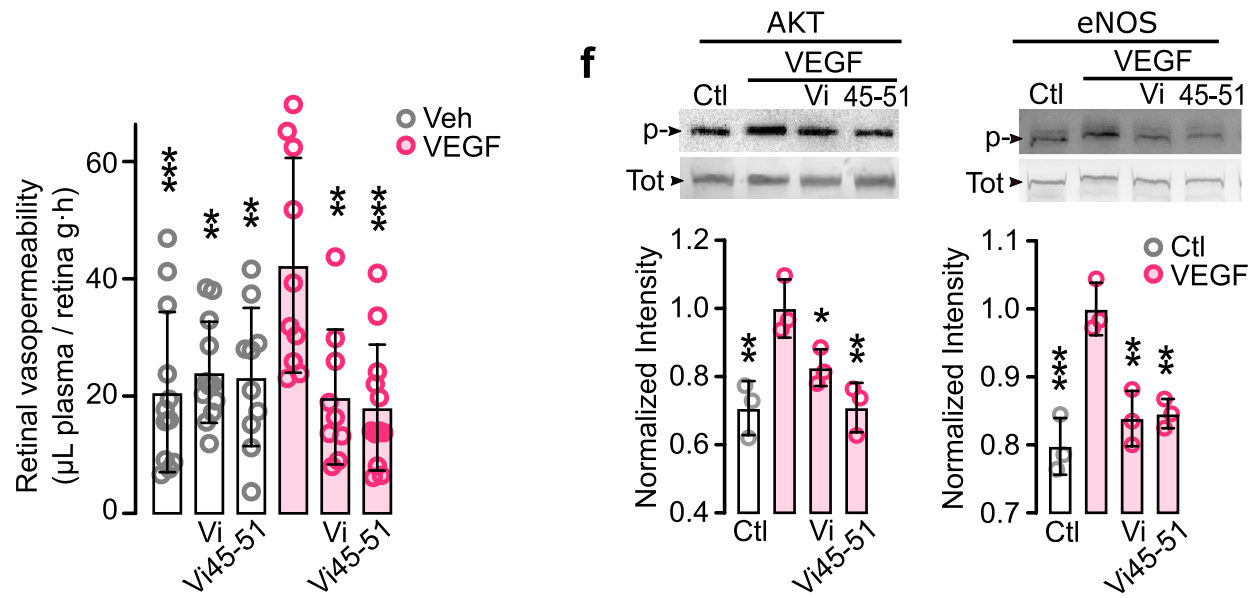

Fig. 6 Vasoinhibin heptapeptide (Vi45-51) containing the HGR motif inhibits vasopermeability in vitro and in vivo. Effect of VEGF, or VEGF and $100 \mathrm{nM} \mathrm{Vi,} \mathrm{or} \mathrm{VEGF} \mathrm{and} 100 \mathrm{nM}$ Vi45-51 on: actin cytoskeleton distribution (200 ng mL $\mathrm{mL}^{-1}$ VEGF) (a), transendothelial-electrical resistance (TEER) (50 ng mL ${ }^{-1}$ VEGF) (b), and flux of Evans blue-linked albumin (BSA) (50 ng $\mathrm{mL}^{-1}$ VEGF) (c) in HUVEC monolayers. $* P<0.001$ versus VEGF. Extravasation of fluo-
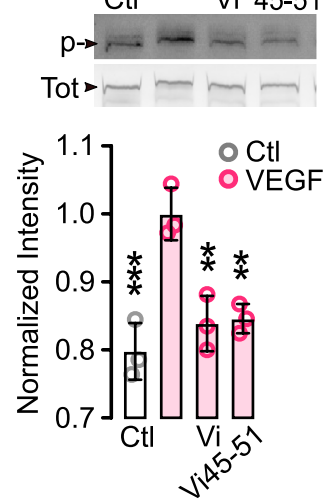

rescein-labeled dextran in flat-mounted retinas (d) and of Evans bluelinked albumin in retinal extracts (e) from rats injected intravitreally with vehicle (Veh), $200 \mathrm{ng}$ VEGF, or VEGF and $20 \mu \mathrm{M} \mathrm{Vi}$, or VEGF and $20 \mu \mathrm{M}$ Vi45-51. $* * P<0.01, * * * P<0.001$ versus VEGF. Values are means $\pm \mathrm{SD}, n=9$, compared by Two-way ANOVA-Dunnett Scale bar: $300 \mu \mathrm{m}(\mathbf{a}), 1 \mathrm{~mm}(\mathbf{d})$ 
a Ac-Thr-His-Gly-Arg-Gly-Phe-Ile- $A m$

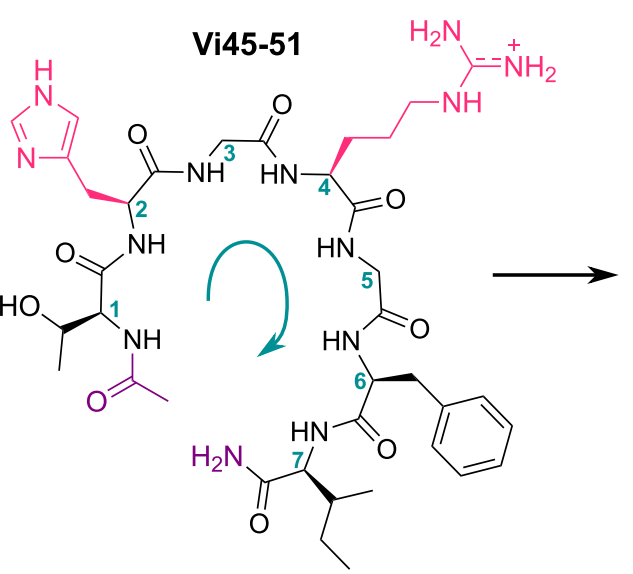

b

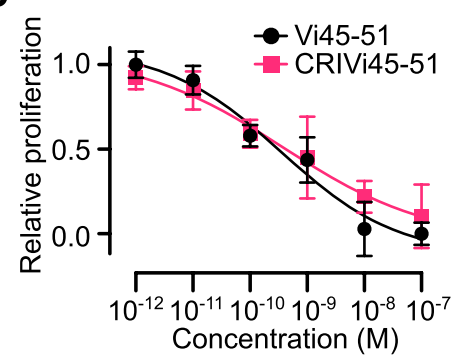

C

Concentration (M)

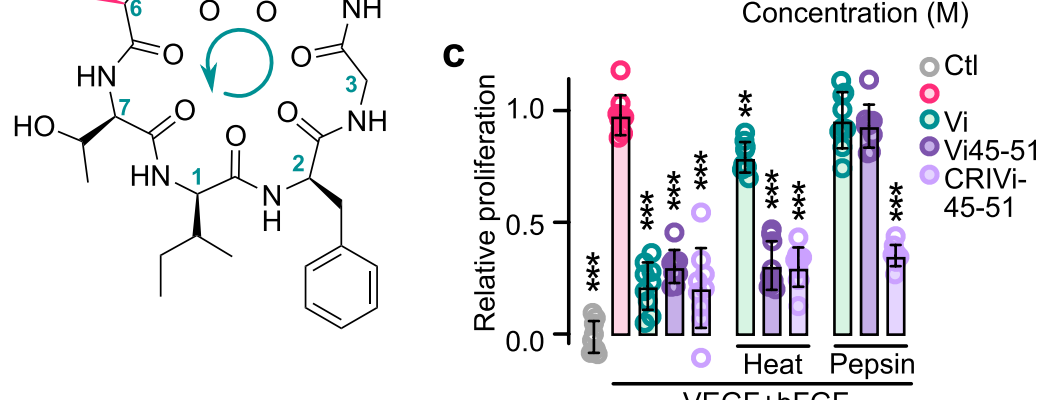

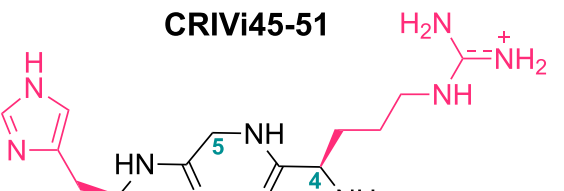

d

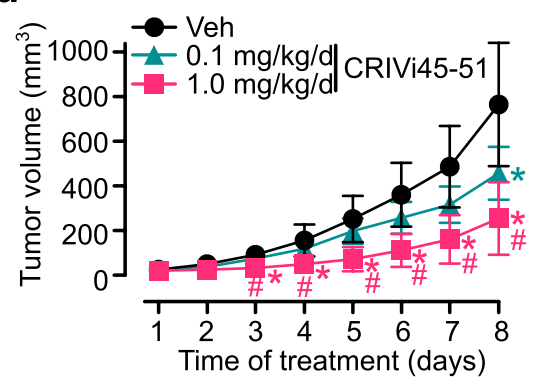

e $\circ$ Veh

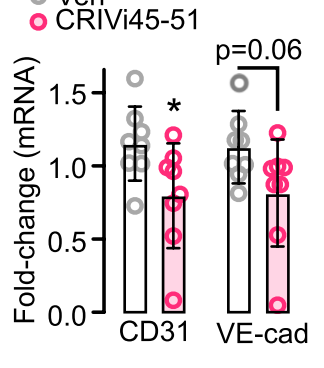

f

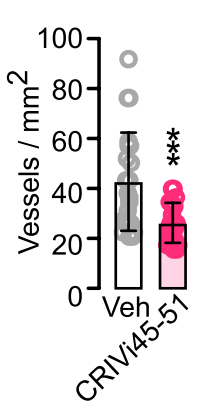

g

VEGF+bFGF

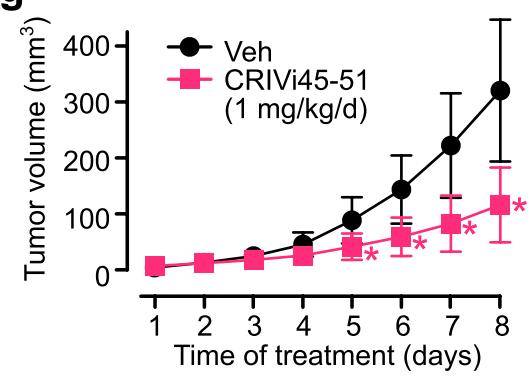

Fig. 7 Oral administration of the cyclic retro-inverse vasoinhibin heptapeptide (CRIVi45-51) reduces tumor growth and vascularization. a Vi45-51 is composed of L-amino acids and acetylated (Ac) and amidated (Am) at the $\mathrm{N}$ - and C-termini, respectively. CRIVi45-51 is composed of D-amino acid in reverse order. Numbers indicate the a-carbons and green arrows the synthesis sense. Note the conserved configuration of HGR side chains (magenta) in the two heptapeptides. b Dose-dependent inhibition of VEGF + bFGF-induced HUVEC proliferation by Vi45-51 or CRIVi45-51. $\mathbf{c}$ Inhibition of VEGF+bFGFinduced HUVEC proliferation by $10 \mathrm{nM}$ vasoinhibin of 123 residues (Vi), Vi45-51, or CRIVi45-51 before or after heat inactivation or

data provides no information regarding the relevance of a therapeutic intervention, unless pharmacokinetic and pharmacodynamic parameters establish the link between both assays.

\section{Oral administration of a cyclic retro-inverse vasoinhibin heptapeptide containing the HGR motif reduces tumor growth and vascularization}

Peptides have limited therapeutic application due to reduced stability and oral bioavailability [12] but substitutions with D-amino acids and cyclization can overcome these limitations [47]. Vi45-51 was optimized into a cyclic retro-inverse pepsin incubation. $* * P<0.01, * * * P<0.001$ versus $\mathrm{VEGF}+\mathrm{bFGF}$ alone. d Growth curves of B16-F10 tumors in mice intravenously injected with vehicle (Veh) or with different doses of CRIVi45-51 after tumor appearance. $* P<0.002$ versus Veh, $\# P<0.002$ versus $0.1 \mathrm{mg} \mathrm{kg}^{-1} \mathrm{~d}^{-1}$. mRNA expression of endothelial cell markers (CD31 and VE-Cad) (e) and vascular density (f) in tumors. ${ }^{*} P<0.05$, $* * * P<0.001$ versus Veh. $\mathrm{g}$ Growth curves of B16-F10 tumors in mice after oral administration of vehicle (Veh) or CRIVi45-51 after tumor appearance. ${ }^{*} P<0.001$ versus Veh. All values are mean $\pm \mathrm{SD}$, $n=9$

peptide (CRIVi45-51) composed of D-amino acids assembled in the reverse order of their native sequence to conserve the configuration of the side chains while conferring resistance to proteolysis (Fig. 7a). CRIVi45-51 inhibited EC proliferation with a similar potency to that of Vi45-51; both peptides retained full activity after heat inactivation, but only CRIVi45-51 was resistant to pepsin degradation (Fig. 7b, c).

Inhibition of angiogenesis by vasoinhibin suppresses the growth of colon, prostate, and melanoma tumors [42, 48, 49]. In view of its antiangiogenic properties and greater stability, CRIVi45-51 is an appealing anti-cancer compound. C57BL6 mice were intradermally implanted with B16-F10 
a

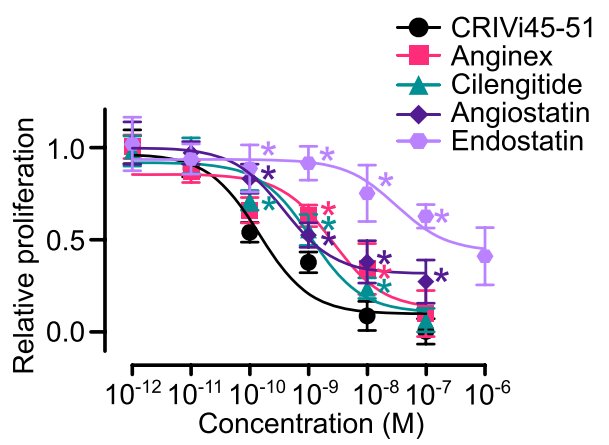

b

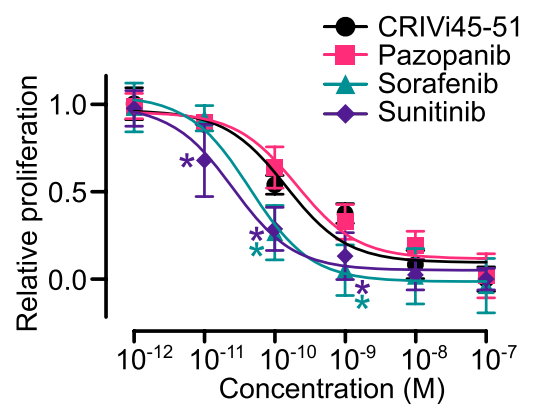

C

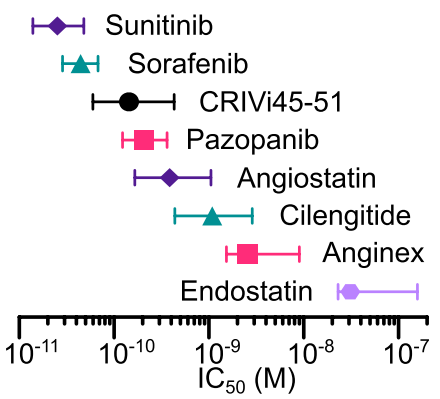

Fig. 8 Potency of the cyclic retro-inverse vasoinhibin heptapeptide (CRIVi45-51) compared to that of other anti-cancer and antiangiogenic drugs. Dose-response inhibition of VEGF + bFGF-induced HUVEC proliferation (a, b) and respective $\mathrm{IC}_{50}$ values (c) of CRIVi45-51, antiangiogenic proteins (angiostatin and endostatin),

melanoma cells and, after tumor appearance, subjected to daily intravenous injections of CRIVi45-51. CRIVi45-51 reduced tumor growth in a dose-related manner, and this effect (Fig. 7d) was associated with reduced angiogenesis. CRIVi45-51 did not inhibit the growth of melanoma cells in vitro (Supplementary Fig. 3), but it did reduce tumor vascular density and expression of CD31 (Fig. 7e, f). Notably, the oral administration of CRIVi45-51 decreased tumor growth with similar efficacy to intravenous delivery (Fig. 7g), indicating improved pharmacological properties. Furthermore, CRIVi45-51 demonstrated a greater potency in inhibiting EC proliferation than other antiangiogenic proteins (endostatin and angiostatin) and peptides (anginex and cilengitide) already tested in cancer clinical trials [11]; its potency is similar to the antiangiogenic tyrosine-kinase inhibitor pazopanib, and lower than the multi-targeted tyrosine-kinase inhibitors sunitinib and sorafenib discontinued from cancer trials due to excessive toxicity (Fig. 8a-c; Supplementary Table 1) [50].

\section{Discussion}

Vasoinhibin is a naturally occurring angiogenesis and vasopermeability inhibitor that holds promise for targeting abnormal growth of the vasculature. A major obstacle for vasoinhibin therapeutic application has been the lack of sufficient functional protein. Post-translational modifications, protein folding, instability, and aggregation complicate the recombinant production of vasoinhibin [23]. Gene therapy vectors have allowed the efficient delivery of vasoinhibin in animal studies $[41,42]$ but are distant from clinical translation. Here, we show that the antiangiogenic and antivasopermeability activities of vasoinhibin reside in a short linear motif of just 3 amino acid residues (HGR) located in the early portion of L1 that upon peptides (anginex, cilengitide), and tyrosine-kinase inhibitors (pazopanib, sorafenib, sunitinib). ${ }^{*} P<0.001$ versus CRIVi45-51. HUVEC proliferation relative to that of the lowest and highest dose of the CRIVi45-51 positive control. Dose-response curves fitted by least square regression analysis $\left(r^{2}<0.7\right)$. All values are mean $\pm \mathrm{SD}, n=9$

mutation leads to vasoinhibin loss of function. Moreover, oligopeptides of 3-7 amino acids containing HGR are as potent as whole vasoinhibin, easy to produce, stable, and orally active for targeting angiogenesis and hyperpermeability in the retina and melanoma tumor vascularization and growth.

The antiangiogenic determinant of vasoinhibin has been a controversial topic. Consistent with our findings, a peptide of 14 amino acids located in the early part of L1 of buffalo PRL, unveiled due to its homology with antiangiogenic human somatostatin, exhibited antiangiogenic properties [26]. However, other work located the activity of vasoinhibin within a-helix $2(\mathrm{H} 2)$, specifically in a 14 amino acid sequence with "tilted peptide" characteristics [51]. This tilted sequence is highly hydrophobic and, when synthesized fused to maltose-binding protein to improve solubility, it did inhibit angiogenesis but with a potency 4- to 32-fold lower than that of vasoinhibin. Moreover, mutation to abolish tilted sequence characteristics only resulted in a partial loss of vasoinhibin function [51].

The fact that full-length PRL is devoid of antiangiogenic properties implies that the HGR motif is not active in full-length PRL. Indeed, we found that exposure of HGR is restricted in PRL due to the formation of salt bridges between R48 and residues E161 and E162 located in H4. We demonstrated the restrictive action of this interaction by showing that alanine substitution of E161 and E162 confers antiangiogenic properties upon PRL. These findings clarify the precise mechanism blocking the antiangiogenic actions in PRL. Notably, the HGR and EE motifs are highly conserved, indicating their convergent evolution to control the PRL effect on angiogenesis and implying that vasoinhibin inhibits blood vessels not only in mammals but also in lower vertebrates [52].

Vasoinhibin originating from PRL comprises a family of isoforms ranging from the first 80 to the first 159 amino acid 
residues, depending on the site of cleavage of different proteases (cathepsin D, matrix metalloproteinases, bone morphogenetic protein 1) $[14,16,24]$. The fact that a short linear motif of only 3 residues is the bioactive determinant suggests that all vasoinhibin isoforms share the same potency. Indeed, vasoinhibin isoforms derived from PRL, GH, and PL are equally potent [43]. The amino acid sequence of PL and GH is remarkably alike ( $86 \%$ homology), whereas human PRL only shares $25 \%$ sequence homology with the other two hormones [13]. The location of the antiangiogenic motif is similar among the three hormones, albeit in the $\mathrm{GH}$ - and PL-derived vasoinhibin isoforms this motif comprises only 2 amino acid residues (QK).

The vasoinhibin domain is an example of short linear motifs (SLiM). SLiM are typically between 3 and 10 amino acids, of which usually just two or three are important for function [53]. SLiM are very common. The updated (2018) SLiM database includes $>1$ million minimotifs in $>180,000$ unique proteins [54]. In particular, the HGR and QGR motifs occur in some proteins, including antiangiogenic collagenderived peptides, such as pentastatin-3 and tetrastatin [55], whereas the QK is much more common $[55,56]$. However, these motifs have not been previously validated experimentally or causally related to angiogenesis. As in vasoinhibin precursor molecules, these SLiM may be under tight regulation, so that their presence may or not confer antiangiogenic properties. For example, the $\mathrm{SH} 3$ binding motif RxPxxP occurs in 1 out of 20 randomly selected proteins, of which only few are functional [53]. Whether or not SLiM are functional would depend on context, including cellular compartmentalization, temporal expression, or, as revealed by our study, post-translational modifications (proteolysis, glycosylation, phosphorylation).

Unveiling the short linear motif of vasoinhibin and its evolutionary conservation has many relevant implications. First, the motif can be explored for drug development, as only few structural modifications would be required to generate soluble agonists and antagonists that are easy to produce and have low toxicity and improved pharmacokinetic properties. Second, the limited number of residues of the functional motif could help identify vasoinhibin binding partners in cell signaling processes and post-translational modifications affecting their properties. Third, the motif could impact the development of antibodies able to discriminate between vasoinhibin and PRL for quantifying vasoinhibin levels in the clinic. Finally, mutations of the vasoinhibin functional motif could be linked to several diseases in humans.

Here, we show that a cyclic retro-inverse heptapeptide is an optimized vasoinhibin analog that is resistant to pepsin degradation and orally active to inhibit vascularization and growth of melanoma tumors in mice. Furthermore, this analog inhibits endothelial cell proliferation with $\mathrm{IC}_{50}$ values in the pM range that are 2.7- to 214-fold lower than those of other antiangiogenic proteins (endostatin and angiostatin) and peptides (anginex and cilengitide) tested in cancer clinical trials [11]. However, significance of comparing the $\mathrm{IC}_{50}$ values of the various angiogenesis inhibitors is limited by the fact that they do not share receptors, co-receptors, and cell components for signaling [57].

Vasoinhibin is the subject of a completed clinical trial on peripartum cardiomyopathy (ClinicalTrial.gov, NCT00998556) and an on-going trial on diabetic retinopathy and diabetic macular oedema (ClinicalTrial.gov, NCT03161652). These trials used dopamine D2 receptor agonist- or antagonist-medications causing hypoprolactinemia or hyperprolactinemia to indirectly downregulate [58] or upregulate [59] vasoinhibin levels, respectively. The current study introduces a potent vasoinhibin analog that is small, stable, orally effective, and easy to produce for the direct clinical treatment of the above diseases and other angiogenesis-related disorders. As vasoinhibin is a broadly acting natural protein $[13,14,16]$, vasoinhibin analogs could counteract the action of several proangiogenic mediators with limited resistance, side effects, and toxicity. The anticipated development of antagonists may increase clinical options for managing insufficient angiogenesis and abnormal vascular regression. Furthermore, antibodies able to discriminate between vasoinhibin and PRL may be developed to solve the on-going challenge of measuring endogenous vasoinhibin levels for diagnostic and interventional purposes.

In conclusion, our findings remove the barrier to using vasoinhibin as a therapeutic agent and provide tools for guiding research into the molecular and physiopathological actions of vasoinhibin and other proteins containing the HGR and related motifs.

Supplementary Information The online version contains supplementary material available at https://doi.org/10.1007/s10456-021-09800-x.

Acknowledgements We thank Xarubet Ruíz-Herrera, Fernando López Barrera, Adriana González Gallardo, Valentín Mendoza Rodríguez, Alejandra Castilla León, José Martín García Servín, María A. Carbajo Mata, Ericka A. de los Ríos Arellano, Nydia Hernández-Ríos, Luis Alberto Aguilar, Alejandro de León Cuevas for their excellent technical assistance, Dorothy Pless for critically editing the manuscript, and Jessica Gonzalez Norris for helping correct its English style.

Author contributions JPR and CC conceived research, designed and supervised the study, interpreted the data, and wrote the manuscript. JPR and MZ performed most research. LMSM, EAC, GRH, and FFN performed research. FLC contributed reagents. RPM contributed to study design and edited the manuscript. JT, TB and GME conceived research, supervised and revised the study. All authors reviewed and approved the manuscript.

Funding This work was supported by grants A1-S-9620B and 289568 from "Consejo Nacional de Ciencia y Tecnología" (CONACYT) and UNAM grant 405PC to C.C. Magdalena Zamora is a doctoral student from 'Programa de Doctorado en Ciencias Biomédicas, Universidad 
Nacional Autónoma de México (UNAM)' and received fellowship 768182 from CONACYT.

Data availability All data generated or analyzed during this study are included in this published article and its supplementary information files.

\section{Declarations}

Conflict of interest The authors declare the following competing interests: C.C., J.P.R., M.Z., G.M.E., J.T., and T.B. are inventors of submitted Mexican (MX/E/2019/079075) and multinational (PCT/ EP2020/069154) patent applications. The Universidad Nacional Autónoma de México (UNAM) and the authors J.T. and T.B. are owners of the pending patents.

Ethical approval All experiments were approved by the Bioethics Committee of the Institute of Neurobiology of the National University of Mexico (UNAM).

Open Access This article is licensed under a Creative Commons Attribution 4.0 International License, which permits use, sharing, adaptation, distribution and reproduction in any medium or format, as long as you give appropriate credit to the original author(s) and the source, provide a link to the Creative Commons licence, and indicate if changes were made. The images or other third party material in this article are included in the article's Creative Commons licence, unless indicated otherwise in a credit line to the material. If material is not included in the article's Creative Commons licence and your intended use is not permitted by statutory regulation or exceeds the permitted use, you will need to obtain permission directly from the copyright holder. To view a copy of this licence, visit http://creativecommons.org/licenses/by/4.0/.

\section{References}

1. Carmeliet P (2003) Angiogenesis in health and disease. Nat Med 9:653-660. https://doi.org/10.1038/nm0603-653

2. Jayson GC, Kerbel R, Ellis LM, Harris AL (2016) Antiangiogenic therapy in oncology: current status and future directions. Lancet 388:518-529. https://doi.org/10.1016/S0140-6736(15) 01088-0

3. Apte RS, Chen DS, Ferrara N (2019) VEGF in signaling and disease: beyond discovery and development. Cell 176:12481264. https://doi.org/10.1016/j.cell.2019.01.021

4. Fallah A, Sadeghinia A, Kahroba H et al (2019) Therapeutic targeting of angiogenesis molecular pathways in angiogenesis-dependent diseases. Biomed Pharmacother 110:775-785. https://doi.org/10.1016/j.biopha.2018.12.022

5. Qin S, Li A, Yi M et al (2019) Recent advances on anti-angiogenesis receptor tyrosine kinase inhibitors in cancer therapy. J Hematol Oncol 12:27. https://doi.org/10.1186/s13045-019-0718-5

6. Bergers G, Hanahan D (2008) Modes of resistance to anti-angiogenic therapy. Nat Rev Cancer 8:592-603. https://doi.org/10. $1038 /$ nrc2442

7. Xu H, Zhao G, Yang J, Wen X (2019) Advances in toxicity risk analysis and effective treatments for targeted antiangiogenic drugs. Int J Clin Exp Med 12:12020-12027

8. Rao N, Lee YF, Ge R (2015) Novel endogenous angiogenesis inhibitors and their therapeutic potential. Acta Pharmacol Sin 36:1177-1190. https://doi.org/10.1038/aps.2015.73
9. Nyberg P, Xie L, Kalluri R (2005) Endogenous inhibitors of angiogenesis. Cancer Res 65:3967-3979. https://doi.org/10. 1158/0008-5472.CAN-04-2427

10. Cao Y (2001) Endogenous angiogenesis inhibitors and their therapeutic implications. Int J Biochem Cell Biol 33:357-369. https://doi.org/10.1016/s1357-2725(01)00023-1

11. Rosca EV, Koskimaki JE, Rivera CG et al (2011) Anti-angiogenic peptides for cancer therapeutics. Curr Pharm Biotechnol 12:1101-1116. https://doi.org/10.2174/138920111796117300

12. Lau JL, Dunn MK (2018) Therapeutic peptides: historical perspectives, current development trends, and future directions. Bioorg Med Chem 26:2700-2707. https://doi.org/10.1016/j. bmc.2017.06.052

13. Clapp C, Thebault S, Jeziorski MC, Martínez De La Escalera G (2009) Peptide hormone regulation of angiogenesis. Physiol Rev 89:1177-1215. https://doi.org/10.1152/physrev.00024.2009

14. Clapp C, Thebault S, Macotela Y et al (2015) Regulation of blood vessels by prolactin and vasoinhibins. Adv Exp Med Biol 846:83-95. https://doi.org/10.1007/978-3-319-12114-7_4

15. Bajou K, Herkenne S, Thijssen VL et al (2014) PAI-1 mediates the antiangiogenic and profibrinolytic effects of $16 \mathrm{~K}$ prolactin. Nat Med 20:741-747. https://doi.org/10.1038/nm.3552

16. Triebel J, Bertsch T, Bollheimer C et al (2015) Principles of the prolactin/vasoinhibin axis. Am J Physiol Regul Integr Comp Physiol ajpregu 00256:2015. https://doi.org/10.1152/ajpregu. 00256.2015

17. Triebel J, Macotela Y, de la Escalera GM, Clapp C (2011) Prolactin and vasoinhibins: endogenous players in diabetic retinopathy. IUBMB Life 63:806-810. https://doi.org/10.1002/iub.518

18. Nuñez-Amaro CD, Moreno-Vega AI, Adan-Castro E et al (2020) Levosulpiride increases the levels of prolactin and antiangiogenic vasoinhibin in the vitreous of patients with proliferative diabetic retinopathy. Transl Vis Sci Technol 9:27-27. https:// doi.org/10.1167/tvst.9.9.27

19. Zepeda-Romero LC, Vazquez-Membrillo M, Adan-Castro E et al (2017) Higher prolactin and vasoinhibin serum levels associated with incidence and progression of retinopathy of prematurity. Pediatr Res 81:473-479. https://doi.org/10.1038/pr.2016.241

20. Hilfiker-Kleiner D, Kaminski K, Podewski E et al (2007) A cathepsin D-cleaved $16 \mathrm{kDa}$ form of prolactin mediates postpartum cardiomyopathy. Cell 128:589-600. https://doi.org/10. 1016/j.cell.2006.12.036

21. Gonzalez C, Parra A, Ramirez-Peredo J et al (2007) Elevated vasoinhibins may contribute to endothelial cell dysfunction and low birth weight in preeclampsia. Lab Invest 87:1009-1017. https://doi.org/10.1038/labinvest.3700662

22. Ortiz G, Ledesma-Colunga MG, Wu Z et al (2020) Vasoinhibin reduces joint inflammation, bone loss, and the angiogenesis and vasopermeability of the pannus in murine antigen-induced arthritis. Lab Invest 100:1068-1079. https://doi.org/10.1038/ s41374-020-0432-5

23. Moreno-Carranza B, Robles JP, Cruces-Solís H et al (2019) Sequence optimization and glycosylation of vasoinhibin: pitfalls of recombinant production. Protein Expr Purif 161:49-56. https://doi.org/10.1016/j.pep.2019.04.011

24. Clapp C, Aranda J, Gonzalez C et al (2006) Vasoinhibins: endogenous regulators of angiogenesis and vascular function. Trends Endocrinol Metab 17:301-307. https://doi.org/10. 1016/j.tem.2006.08.002

25. Robles JP, Zamora M, Velasco-Bolom JL et al (2018) Vasoinhibin comprises a three-helix bundle and its antiangiogenic domain is located within the first 79 residues. Sci Rep 8:17111. https://doi.org/10.1038/s41598-018-35383-7

26. Lee J, Majumder S, Chatterjee S, Muralidhar K (2011) Inhibitory activity of the peptides derived from buffalo prolactin on angiogenesis. J Biosci 36:341-354 
27. Galfione M, Luo W, Kim J et al (2003) Expression and purification of the angiogenesis inhibitor 16-kDa prolactin fragment from insect cells. Protein Expr Purif 28:252-258

28. Keeler C, Dannies PS, Hodsdon ME (2003) The tertiary structure and backbone dynamics of human prolactin. J Mol Biol 328:1105-1121. https://doi.org/10.1016/s0022-2836(03) 00367-x

29. Van Der Spoel D, Lindahl E, Hess B et al (2005) GROMACS: fast, flexible, and free. J Comput Chem 26:1701-1718. https://doi.org/ $10.1002 /$ jcc. 20291

30. Teilum K, Hoch JC, Goffin V et al (2005) Solution structure of human prolactin. J Mol Biol 351:810-823. https://doi.org/10. 1016/j.jmb.2005.06.042

31. Baudin B, Bruneel A, Bosselut N, Vaubourdolle M (2007) A protocol for isolation and culture of human umbilical vein endothelial cells. Nat Protoc 2:481-485. https://doi.org/10.1038/nprot.2007. 54

32. Salic A, Mitchison TJ (2008) A chemical method for fast and sensitive detection of DNA synthesis in vivo. Proc Natl Acad Sci U S A 105:2415-2420. https://doi.org/10.1073/pnas.0712168105

33. Liang CC, Park AY, Guan JL (2007) In vitro scratch assay: a convenient and inexpensive method for analysis of cell migration in vitro. Nat Protoc 2:329-333. https://doi.org/10.1038/nprot. 2007.30

34. Carpenter AE, Jones TR, Lamprecht MR et al (2006) Cell Profiler: image analysis software for identifying and quantifying cell phenotypes. Genome Biol 7:R100. https://doi.org/10.1186/ gb-2006-7-10-r100

35. Justus CR, Leffler N, Ruiz-Echevarria M, Yang LV (2014) In vitro cell migration and invasion assays. J Vis Exp 88:51046. https:// doi.org/10.3791/51046

36. Brown RM, Meah CJ, Heath VL et al (2016) Tube-forming assays. In: Martin SG, Hewett PW (eds) Angiogenesis protocols. Springer, New York, pp 149-157

37. Carpentier G, Berndt S, Ferratge S et al (2020) Angiogenesis analyzer for ImageJ-a comparative morphometric analysis of "Endothelial Tube Formation Assay" and "Fibrin Bead Assay." Sci Rep 10:11568. https://doi.org/10.1038/s41598-020-67289-8

38. Malinda KM (2009) In vivo matrigel migration and angiogenesis assay. In: Murray C, Martin S (eds) Angiogenesis protocols, 2nd edn. Humana Press, Totowa, pp 287-294

39. Coltrini D, Di Salle E, Ronca R et al (2013) Matrigel plug assay: evaluation of the angiogenic response by reverse transcriptionquantitative PCR. Angiogenesis 16:469-477. https://doi.org/10. 1007/s10456-012-9324-7

40. Vázquez-Membrillo M, Siqueiros-Márquez L, Núñez FF et al (2020) Prolactin stimulates the vascularization of the retina in newborn mice under hyperoxia conditions. J Neuroendocrinol 32:e12858. https://doi.org/10.1111/jne. 12858

41. Ramírez M, Wu Z, Moreno-Carranza B et al (2011) Vasoinhibin gene transfer by adenoassociated virus type 2 protects against VEGF- and diabetes-induced retinal vasopermeability. Invest Ophthalmol Vis Sci 52:8944-8950. https://doi.org/10.1167/iovs. 11-8190

42. Nguyen NQ, Cornet A, Blacher S et al (2007) Inhibition of tumor growth and metastasis establishment by adenovirus-mediated gene transfer delivery of the antiangiogenic factor 16K hPRL. Mol Ther 15:2094-2100. https://doi.org/10.1038/sj.mt.6300294

43. Struman I, Bentzien F, Lee H et al (1999) Opposing actions of intact and $\mathrm{N}$-terminal fragments of the human prolactin/growth hormone family members on angiogenesis: an efficient mechanism for the regulation of angiogenesis. Proc Natl Acad Sci U S A 96:1246-1251

44. Stahl A, Connor KM, Sapieha P et al (2010) The mouse retina as an angiogenesis model. Invest Ophthalmol Vis Sci 51:2813-2826. https://doi.org/10.1167/iovs.10-5176
45. Arredondo Zamarripa D, Diaz-Lezama N, Melendez Garcia R et al (2014) Vasoinhibins regulate the inner and outer blood-retinal barrier and limit retinal oxidative stress. Front Cell Neurosci 8:333. https://doi.org/10.3389/fncel.2014.00333

46. Garcia C, Aranda J, Arnold E et al (2008) Vasoinhibins prevent retinal vasopermeability associated with diabetic retinopathy in rats via protein phosphatase $2 \mathrm{~A}$-dependent eNOS inactivation. $\mathrm{J}$ Clin Invest 118:2291-2300. https://doi.org/10.1172/JCI34508

47. Nielsen DS, Shepherd NE, Xu W et al (2017) Orally absorbed cyclic peptides. Chem Rev 117:8094-8128. https://doi.org/10. 1021/acs.chemrev.6b00838

48. Bentzien F, Struman I, Martini JF et al (2001) Expression of the antiangiogenic factor $16 \mathrm{~K}$ hPRL in human HCT116 colon cancer cells inhibits tumor growth in Rag1(-/-) mice. Cancer Res 61:7356-7362

49. Kim J, Luo W, Chen DT et al (2003) Antitumor activity of the $16-\mathrm{kDa}$ prolactin fragment in prostate cancer. Cancer Res 63:386-393

50. Haas NB, Manola J, Uzzo RG et al (2016) Adjuvant sunitinib or sorafenib for high-risk, non-metastatic renal-cell carcinoma (ECOG-ACRIN E2805): a double-blind, placebo-controlled, randomised, phase 3 trial. Lancet 387:2008-2016. https://doi.org/10. 1016/S0140-6736(16)00559-6

51. Nguyen N-Q-N, Tabruyn SP, Lins L et al (2006) Prolactin/growth hormone-derived antiangiogenic peptides highlight a potential role of tilted peptides in angiogenesis. Proc Natl Acad Sci USA 103:14319-14324. https://doi.org/10.1073/pnas.0606638103

52. Clapp C, Martínez de la Escalera L, Martínez de la Escalera G (2012) Prolactin and blood vessels: a comparative endocrinology perspective. Gen Comp Endocrinol 176:336-340. https://doi.org/ 10.1016/j.ygcen.2011.12.033

53. Neduva V, Russell RB (2005) Linear motifs: evolutionary interaction switches. FEBS Lett 579:3342-3345. https://doi.org/10. 1016/j.febslet.2005.04.005

54. Lyon KF, Cai X, Young RJ et al (2018) Minimotif Miner 4: a million peptide minimotifs and counting. Nucleic Acids Res 46:D465-D470. https://doi.org/10.1093/nar/gkx1085

55. Karagiannis ED, Popel AS (2008) A systematic methodology for proteome-wide identification of peptides inhibiting the proliferation and migration of endothelial cells. Proc Natl Acad Sci USA 105:13775. https://doi.org/10.1073/pnas.0803241105

56. Blanco JL, Porto-Pazos AB, Pazos A, Fernandez-Lozano C (2018) Prediction of high anti-angiogenic activity peptides in silico using a generalized linear model and feature selection. Sci Rep 8:15688. https://doi.org/10.1038/s41598-018-33911-z

57. Aykul S, Martinez-Hackert E (2016) Determination of halfmaximal inhibitory concentration using biosensor-based protein interaction analysis. Anal Biochem 508:97-103. https://doi.org/ 10.1016/j.ab.2016.06.025

58. Hilfiker-Kleiner D, Haghikia A, Berliner D et al (2017) Bromocriptine for the treatment of peripartum cardiomyopathy: a multicentre randomized study. Eur Heart J 38:2671-2679. https:// doi.org/10.1093/eurheartj/ehx355

59. Robles-Osorio ML, García-Franco R, Núñez-Amaro CD et al (2018) Basis and design of a randomized clinical trial to evaluate the effect of levosulpiride on retinal alterations in patients with diabetic retinopathy and diabetic macular edema. Front Endocrinol (Lausanne) 9:242. https://doi.org/10.3389/fendo.2018. 00242

Publisher's Note Springer Nature remains neutral with regard to jurisdictional claims in published maps and institutional affiliations. 